\title{
Comunicació de males notícies en context sanitari
}

\author{
Marta Consuegra-Fernández ${ }^{1}$ i Alejandra Fernández-Trujillo ${ }^{1,2}$ \\ ${ }^{1}$ Departament de Filologia Hispànica, Teoria de la Literatura i Comunicació, \\ Facultat de Filologia i Comunicació, Universitat de Barcelona \\ ${ }^{2}$ Unitat de Cures Intensives, Corporació Sanitària Parc Taulí Hospital \\ Universitari, Barcelona \\ mconsuegra@ub.edu \\ argenteaft_3@hotmail.com
}

Recepció: 09/03/2021, acceptació: 18/06/2021

Resum: Malgrat considerar-se una pràctica clínica de menor rellevància, la comunicació de males notícies en context sanitari és una de les tasques més difícils i amb major impacte emocional tant per a la persona atesa i els familiars propers com per al mateix metge. Si bé el pacient és, en aquest cas, l'eix central de la situació, tots els interlocutors experimenten dificultats pròpies que poden impedir una comunicació eficient, comportar conseqüències emocionals negatives i, en última instància, deteriorar la relació sanitària. En aquest sentit, és important reconèixer les veus de tots els protagonistes d'aquesta interacció i identificar quins són els reptes que cal afrontar a cada cas per poder atendre les seves necessitats i aconseguir una comunicació satisfactòria.

Paraules clau: males notícies, comunicació, sanitat.

\section{Comunicación de malas noticias en contexto sanitario}

Resumen: A pesar de considerarse una práctica clínica de menor relevancia, la comunicación de malas noticias en contexto sanitario es una de las tareas más difíciles y con mayor impacto emocional tanto para la persona atendida y sus allegados como para el propio médico. Si bien el paciente es, en este caso, el eje central de la situación, los dos interlocutores experimentan dificultades propias que pueden impedir una comunicación eficiente, acarrear consecuencias emocionales negativas y, en última instancia, dañar la relación sanitaria. En este sentido, es importante reconocer las voces de todos los protagonistas de esta interacción e identificar cuáles son los desafíos que afrontan en cada caso para poder atender a sus necesidades y conseguir una comunicación satisfactoria.

Palabras clave: malas noticias, comunicación, sanidad.

\section{Breaking bad news in healthcare}

Abstract: Despite being considered a less-relevant clinical practice, the communication of bad news is one of the tasks that is the most difficult and has the greatest emotional impact on the person being treated and their relatives, and the doctor themselves. Although the patient plays the most important role in this situation, the two interlocutors 
each experience their own challenges, which can impede efficient communication. Eventually, this may have negative emotional consequences and ultimately damage the patient-provider relationship. In this sense, it is important to recognise the voices of all actors in this interaction and to identify the challenges they face. Achieving satisfactory communication means first recognising that the needs of each speaker have to be met.

Keywords: bad news, communication, healthcare.

\section{INTRODUCCIÓ}

La comunicació de males notícies a pacients o els seus acompanyants és una de les comeses més difícils i complexes de la pràctica clínica. Es tracta d'una conversa que, per la seva naturalesa, té un gran impacte emocional i, si no es gestiona adequadament, pot causar un patiment afegit i deteriorar irreversiblement la relació sanitària (Ptacek, Eberhardt, 1996).

Entenem per mala notícia aquella que modifica radicalment i negativament la perspectiva del pacient, o dels seus familiar i persones properes, respecte al seu futur (Buckman, 1984). No obstant, més enllà del component objectiu de severitat al qual es fa referència quan s'informa de males notícies, existeix un component subjectiu que depèn del mateix pacient i que es veu condicionat pel context psicosocial que l'envolta. És a dir, la notícia sobre un diagnòstic de menor gravetat pot desencadenar una reacció emocional tant o més intensa que la d'un altre de més greu segons el context mencionat.

El ventall de possibles males notícies és molt ampli i la reacció emocional dependrà, a més, de múltiples factors com ara l'edat, les responsabilitats o els valors i creences de cada pacient. Tots aquests i altres elements condicionants modulen les expectatives de la persona que rep la notícia; com més grans siguin, major serà l'impacte emocional (Sobrino López, 2008). No sorprèn, per tant, la diversitat de respostes que es poden ocasionar arran d'una informació potencialment negativa però ineludible, tant per al professional sanitari com per a la persona atesa.

El paternalisme mèdic clàssic, present també avui, es fonamentava en el reconeixement clínic i la resolució de problemes mèdics, un patró relacional asimètric en el qual el metge assumia tota la responsabilitat i prenia les decisions del pacient segons els principis de beneficència i no maleficència (Consuegra et al., 2020). En aquest context, era freqüent ocultar informació clínica potencialment dolorosa a la persona malalta (Oken, 1961), limitar-la o maquillar-la amb eufemismes per tal d'evitar el patiment dels pacients i familiars (Campbell, 2021; Caswell et al., 2015; De Moura Villela et al., 2020; DeForest, 2019; Dos Santos et al., 2021; Kelley \& Morrison, 2015; Maynard, 2017; Sanders, 2015; VandeKieft, 2001).

Actualment, el patró paternalista s'està reemplaçant per models més horitzontals que defensen el principi d'autonomia i dret a la informació del pacient. Aquest escenari propicia el respecte pels valors i voluntats de la persona atesa, fet que té diversos beneficis (Consuegra et al., 2020) tant en l'adherència al tractament i la recuperació de la malaltia com en el benestar emocional dels interlocutors.

En aquest nou escenari, és imprescindible que el pacient conegui i comprengui tota la informació relativa a la seva malaltia i prengui les seves pròpies decisions respecte al seu procés terapèutic adequadament. De fet, aquesta és la voluntat expressada per la majoria de pacients amb diagnòstics de malalties greus com el càncer (Rubio Arribas et al., 2004). La transmissió de la informació mèdica al pacient, sigui positiva o negativa, no només és un acte ètic, sinó que també respon a un deure del professional sanitari, tal com recullen la Llei general de sanitat i la Llei 41/2002, del Codi civil, a excepció de casos puntuals. 
La comunicació amb el pacient, tot i tractar-se d'una competència exigida pel professional sanitari, rep menys consideració en comparació amb altres aspectes de l'assistència mèdica i sovint no se'n preveu una formació acadèmica específica. En conseqüència, els treballadors sanitaris no se senten preparats (García Díaz, 2006) i s'exposen a una situació particularment delicada sense disposar de suficients eines ni recursos comunicatius per gestionar-la de la millor manera possible. Aquest obstacle se suma a l'impacte emocional de la notícia i moltes vegades acaba convertint-se en motiu de queixes per part de malalts i familiars. En aquest sentit, cal distingir si les queixes procedeixen de la possible manca de qualitat comunicativa o bé del mateix contingut negatiu de les notícies, que pot despertar recel dels pacients cap al metge que les notifica. És important reconèixer que una informació potencialment agressiva o amb un gran pes emocional podria quedar vinculada a aquella persona que la comunica. Això distancia la relació sanitària i pot acabar desembocant en un conflicte major.

Els principals protagonistes en la comunicació de males notícies són els receptors, els pacients i els familiars, ja que, en última instància, seran els qui patiran el cop emocional més fort. No obstant, si la comunicació entre metge i pacient no és satisfactòria, això perjudicarà ambdós interlocutors, $\mathrm{i}$, per tant, cadascú té una responsabilitat a l'hora de minimitzar el patiment ocasionat en l'altre i protegir la relació sanitària.

\section{Obstacles En la COMUNiCACió de MALES Notícies}

L'eix de la comunicació es determina sempre en funció de l'estat del pacient, la seva capacitat, disposició i, sobretot, voluntat expressa de rebre la informació. Tot i que la bibliografia suggereix que la majoria de pacients amb càncer avançat volen conèixer el seu diagnòstic i rebre informació detallada sobre el pronòstic, aquesta voluntat varia no només entre individus, sinó també en una mateixa persona amb el pas del temps (Russell, Ward, 2011). Això obliga el metge a haver de conèixer les necessitats i desitjos de cada pacient en tot moment i adaptar de forma individualitzada el missatge. És el pacient qui decideix què vol saber i el metge ha de respondre a aquesta petició, i ho ha de fer de manera comprensible i clara.

No hi ha dubte que la complexitat dels processos patològics i els tecnicismes mèdics requereixen que el professional sanitari utilitzi un llenguatge entenedor. No es pot exigir que els pacients comprenguin una informació tècnica, malgrat que actualment disposin de major accés a conceptes mèdics a través d'internet $o$ altres mitjans no especialitzats, $o$ que tinguin la capacitat d'entendre la gravetat de la seva condició de salut davant d'una situació extrema.

En un escenari tan complex i delicat com la comunicació de males notícies, és imprescindible analitzar les principals interferències que hi pugui haver, i això inclou, ineludiblement, les barreres que afronten les dues parts. El coneixement mutu de les dificultats i vulnerabilitats de l'altre permetrà minimitzar l'angoixa ocasionada en una direcció i en l'altra, i també disminuir-ne l'impacte emocional.

\subsection{El professional sanitari}

Informar el pacient sobre procediments i resultats és inherent a la pràctica clínica. Aquesta responsabilitat normalment recau en el metge que directament atén el pacient, i, per tant, és ple coneixedor del seu procés terapèutic.

A ningú li agrada donar males notícies, i el professional sanitari no n'és l'excepció. Aquest és un fenomen ben estudiat i reconegut per la psicologia social: l'efecte MUM, de les sigles en anglès Mum about Undesirable Messages, o silenci sobre els missatges no desitjats (Rosen, Tesser, 1970). Aquesta resistència és el resultat d'inferir la reticència 
dels altres a escoltar una determinada informació i la pròpia, per por que la reacció emocional del receptor pugui també afectar l'emissor.

En medicina, afrontar aquest fenomen genera estrès, angoixa, sensació de culpabilitat i por de ser jutjats negativament (Scarff et al., 2019). Aquesta resposta s'ha associat a la naturalesa de la seva formació professional: curar, salvar, no infringir dolor i disminuir el patiment. En aquest sentit, transmetre una notícia potencialment dolorosa desperta, generalment, rebuig per part del professional sanitari (García Díaz, 2006), que, en última instància, pot adoptar actituds evasives i minimitzar la gravetat de la situació. Fins i tot, aquesta por de l'absència de tractament o de la impossibilitat de curar podria conduir a l'acarnissament terapèutic ${ }^{1}$ com un intent desesperat de vèncer el sentiment de fracàs professional.

La dificultat per gestionar les pròpies emocions se suma al temor de mostrar-se vulnerable, ja que qualsevol reacció emocional pot considerar-se poc professional i debilitar la imatge del metge davant el pacient (García Díaz, 2006). El fet de bloquejar aquesta resposta no només pot resultar perjudicial per al mateix professional sanitari, sinó també per al seu interlocutor pacient, que percep una manca d'empatia, amb la qual cosa la relació sanitària entre ambdós es distancia ineludiblement.

Una manera de vèncer aquesta barrera comunicativa per part del professional passaria per reconèixer les pròpies emocions davant el conflicte que suposa donar una mala notícia. Habitualment el professional aprèn a transmetre males notícies a pacients i familiars amb l'experiència, tot $\mathrm{i}$ que no hi ha evidències que la pròpia pràctica sigui suficient per garantir un aprenentatge comunicatiu en aquesta direcció (Fallowfield, Jenkins, 2004).

És habitual l'ús d'eufemismes o fórmules per vestir amb paraules amables notícies desagradables per suavitzar la gravetat de la situació i mitigar el dolor (Campbell, 2021; Caswell et al., 2015; De Moura Villela et al., 2020; DeForest, 2019; Dos Santos et al., 2021; Kelley, Morrison, 2015; Maynard, 2017; Sanders, 2015; VandeKieft, 2001). Aquests missatges o la manera de transmetre'ls poden despertar rebuig o, fins i tot, augmentar l'agressivitat.

L'habilitat de tractar amb situacions tan complexes com aquesta pot adquirir-se amb una formació específica que permeti als professionals sanitaris viure amb menor angoixa la comunicació de males notícies i sentir-se confortables amb el rol de metge fins i tot en circumstàncies adverses.

Per això és imprescindible incorporar l'estudi de la comunicació dins del currículum acadèmic mèdic per, en primer lloc, protegir la pròpia imatge i evitar l'ús de barreres emocionals i, en segon lloc, sensibilitzar el col-lectiu sobre el malestar físic i emocional del pacient i poder comprendre la seva situació des d'una posició més propera.

Per últim, els darrers anys, han augmentat considerablement de demandes a metges per part d'usuaris de salut (Moore et al., 2000) i moltes d'elles estan relacionades amb una comunicació sanitària deficient (Añel-Rodríguez et al., 2015; Rodríguez Pérez \& Joga, 2010). Conscienciar els professionals que una millor comunicació amb els seus pacients podria disminuir aquestes demandes possiblement ajudaria a reduir la por de represàlies i a centrar l'atenció en la bona pràctica clínica.

\subsection{El pacient $i$ els familiars o acompanyants}

\footnotetext{
${ }^{1}$ Situació en què una persona que es troba en estat terminal o d'agonia per afecció d'una malaltia greu i irreversible rep mesures de suport vital sense utilitat clínica que únicament allarguen la seva vida biològica, sense possibilitats reals de millora o de recuperació, sent, per tant, susceptibles de retirar-se (Junta de Andalucía, 2010).
} 
De la mateixa manera que els metges es resisteixen a donar males notícies, el pacient $\mathrm{i}$ els seus acompanyants també es resisteixen a escoltar-les, i sovint la negació, la desconfiança o la ira són reaccions habituals (Bascuñán et al., 2007). Hi ha veritats molt difícils d'escoltar, i aquestes reaccions ambivalents i contradictòries són esperables dins del mateix procés d'acceptació (Bascunán R., 2013). En aquest sentit, és important reconèixer les pròpies emocions i no projectar-les a l'emissor.

El paradigma d'atenció sanitària actual defensa que el pacient prengui les decisions clíniques respecte a la seva salut, i, per tant, que sigui ple coneixedor del progrés de la seva malaltia. És contradictori, doncs, culpar el missatger quan se l'informa de l'empitjorament de la seva condició mèdica o recriminar-lo de no haver transmès esperances tot i tractar-se d'un pronòstic desfavorable. De fet, i malgrat basar-se en expectatives irreals, els pacients consideren més compassius i més fiables aquells metges que són més optimistes (Tanco et al., 2015).

L'ocultació de la veritat o el fet de maquillar-la s'ha sostingut principalment sota el principi de no maleficència, davant el risc de causar un dany emocional major que el de la mateixa malaltia (Bascuñán R., 2013). Tot i així, les evidències demostren que els beneficis psicològics de conèixer i comprendre la veritat amb certesa i precisió, per molt dura que sigui, són majors i faciliten l'acceptació de la malaltia (Sullivan et al., 2001). I és que la transmissió de falses expectatives a la llarga frustren tant la persona atesa com el professional sanitari (Smith, 2001).

La comunicació de la veritat a un malalt que la demana i que clínicament es troba en disposició de rebre-la és una forma de respecte i constitueix la base de qualsevol relació de confiança (Brewin, Sparshott, 1996).

Davant d'una veritat desesperançadora, però, el pacient es pot plantejar les limitacions del coneixement mèdic i la potencial incertesa de la predicció clínica. No obstant, cal veure la comunicació de la veritat com una oportunitat d'acompanyar el pacient en la presa de decisions en la qual es comparteix una informació que el mateix malalt desitja conèixer i, inevitablement, la incertesa també forma part d'aquesta informació (Bascuñán R., 2013).

En aquest sentit, regatejar informació sobre el progrés de la malaltia o les condicions de salut exposa el metge a una situació controvertida en la qual es veu pressionat a fer afirmacions que sovint l'allunyen del pronòstics més probables.

\section{Conclusions}

La medicina té limitacions, i això comporta que la persona atesa no sempre pugui rebre un tractament eficaç que curi la seva malaltia. Així, en la pràctica diària els metges sovint es veuen obligats a donar males notícies als pacients i a les seves famílies. Malauradament, no existeix una fórmula màgica de com transmetre aquesta informació de la millor manera, però sí que hi ha evidències que un enfocament més humanista $\mathrm{i}$ protocol-litzat, conjuntament amb l'aprenentatge de certes habilitats comunicatives, pot ajudar la gestió emocional de la notícia.

Els obstacles a una comunicació tan delicada són diversos: el pacient i els seus familiars poden qüestionar la informació rebuda, negar-se a acceptar la notícia o, fins i tot, culpar-ne el professional sanitari. Aquest últim pot sentir-se obligat a ocultar les seves pròpies emocions, sentir-se frustrat davant la incapacitat de curar o complir les expectatives terapèutiques i posar barreres emocionals que refredin la relació assistencial.

La resposta del pacient $\mathrm{i}$ els seus familiars depèn, en gran mesura, de la forma en la qual l'emissor transmet la notícia i, de la mateixa manera, el metge es veu condicionat per les expectatives prèvies i reaccions emocionals del pacient i dels seus acompanyants. Així,

Comunicació de males notícies en context sanitari

Marta Consuegra-Fernández, Alejandra Fernández-Trujillo (2021)

Llengua, Societat i Comunicació, núm. $19 \quad$ http://revistes.ub/index.php/LSC/

lsc@ub.edu ～http://creativecommons.org/licenses/by-nc-nd/4.0 doi:10.1344/LSC-2021.19.8 
malgrat que el pacient sigui el protagonista sempre, cal reconèixer tots els interlocutors a l'hora de dissenyar estratègies per millorar significativament aquesta comunicació particularment difícil i incòmoda. Per aquest motiu, és essencial identificar i conèixer les dificultats, necessitats i preferències que afecten tots els implicats.

"When the shadow of death approaches, life and time become more precious. Deeper meanings and clearer priorities often emerge for the dying person. He or she is forced to examine what makes a life meaningful. By sharing burdens, insight, and support, patients and professionals can pursue these discoveries together». [Quan s'acosta l'ombra de la mort, la vida i el temps es tornen més preciosos. Sovint sorgeixen significats més profunds i prioritats més clares per a la persona malalta. Es veu obligada a examinar què fa que la vida tingui sentit. En compartir càrregues, visió i suport, els pacients i els professionals poden fer aquests descobriments junts] (Phipps, Cuthill, 2002).

\section{REFERÈNCIES BibLIOGRÀFIQUES}

AÑel-Rodríguez, R. M., Cambero-Serrano, M. I., i Irurzun-Zuazabal, E. (2015). Análisis de las reclamaciones de pacientes en Atención Primaria: una oportunidad para mejorar la seguridad clínica. Revista de Calidad Asistencial, 3o(5), 220-225. https://doi.org/10.1016/j.cali.2015.04.007

Bascuñán, M., Roizblatt, A. i Roizblatt, D. (2007). Giving bad news in medicine: an exploratory study. Rev Med Univ Navarra, 51(2), 28-31. https://pubmed.ncbi.nlm.nih.gov/17886712/

Bascuñán R., M. L. (2013). Comunicación de "malas noticias" en salud. Revista Médica Clínica Las Condes, 24(4), 685-693. https://doi.org/10.1016/so716-8640(13)70208-6

Brewin, T. i Sparshott, M. (1996). Relating to the Relatives: Breaking Bad News, Communication and Support. CRC Press. https://www.amazon.es/Relating-Relatives-Breaking-Communication-Support/dp/18577 50810

Buckman, R. (1984). Breaking bad news: Why is it still so difficult? British Medical Journal, 288(6430), 1597-1599. https://doi.org/10.1136/bmj.288.6430.1597

CAmpbell, I. (2021). Paramedic delivery of bad news: A novel dilemma during the COVID-19 crisis. Journal of Medical Ethics, 47(1), 16-19. https://doi.org/10.1136/medethics-2020-106710

Caswell, G., Pollock, K., Harwood, R. i Porock, D. (2015). Communication between family carers and health professionals about end-of-life care for older people in the acute hospital setting: A qualitative study. BMC Palliative Care, 14(1). https://doi.org/10.1186/s12904-015-0032-o

Consuegra, M., Girbal, E., Escarrabill, J. i Sitges, M. (2020). Análisis de la comunicación médico-paciente en el Hospital Clínic: diferencias autoperceptuales entre médicos y pacientes. $X P A \quad \& \quad$ Health Communication, $O(3)$. http://www.xpabcn.com/revista/index.php/XPAHC/article/view/31

De Moura Villela, E. F., Bastos, L. K., De Almeida, W. S., Ana, Pereira, A. O., De Paula Rocha, M. S., De Oliveira, F. M. i Bollela, V. R. (2020). Effects on Medical Students of Longitudinal Small-Group Learning about Breaking Bad News. The Permanente Journal, 24. https://doi.org/10.7812/TPP/19.157

DeForest, A. (2019). Better words for better deaths. New England Journal of Medicine, 
380(3), 211-213. https://doi.org/10.1056/NEJMp1810018

Dos Santos, K. L., Gremigni, P., Casu, G., Zaia, V., i Montagna, E. (2021). Development and validation of The Breaking Bad News Attitudes Scale. BMC Medical Education, 21(1), 196. https://doi.org/10.1186/s12909-021-02636-5

Fallowfield, L. i Jenkins, V. (2004). Communicating sad, bad, and difficult news in medicine. The Lancet, 363(9405), 312-319. https://doi.org/10.1016/So140-6736(03)15392-5

García Díaz, F. (2006). Comunicando malas noticias en Medicina: recomendaciones para hacer de la necesidad virtud. Medicina Intensiva, 3O(9). http://scielo.isciii.es/scielo.php?script=sci_arttext\&pid=So210-56912006000900006

JunTa De Andalucía (2010). Ley 2/2010, de 8 de abril, de Derechos y Garantías de la Dignidad de la Persona en el Proceso de la Muerte. https://www.juntadeandalucia.es/boja/2010/88/1

Kelley, A. S. i Morrison, R. S. (2015). Palliative Care for the Seriously Ill. New England Journal of Medicine, 373(8), 747-755. https://doi.org/10.1056/NEJMra1404684

MaYnARD, D. W. (2017). Delivering bad news in emergency care medicine. Acute Medicine \& Surgery, 4(1), 3-11. https://doi.org/10.1002/ams2.210

Moore, P. J., Adler, N. E. i Robertson, P. A. (2000). Medical malpractice: The effect of doctor-patient relations on medical patient perceptions and malpractice intentions. Western Journal of Medicine, 173(4), 244-250. https://doi.org/10.1136/ewjm.173.4.244

Oken, D. (1961). What to Tell Cancer Patients: A Study of Medical Attitudes. JAMA: The Journal of the American Medical Association, 175(13), 1120-1128. https://doi.org/10.1001/jama.1961.03040130004002

Phipps, L. L. i CuthilL, J. D. (2002). Breaking bad news: a clinician's view of the literature. Ann $R$ Coll Physicians Surg Can, 35(5), 287-293. https://pubmed.ncbi.nlm.nih.gov/12812230/

Ptacek, J. T. i Eberhardt, T. L. (1996). Breaking Bad News. JAMA, 276(6), 502. https://doi.org/10.1001/jama.1996.03540060072041

Rodríguez Pérez, A. I. i Joga, M. do M. (2010). Análisis de las reclamaciones de los usuarios de un área de atención primaria. Cuadernos de Atención Primaria, 17(2), 92-96. https://dialnet.unirioja.es/servlet/articulo?codigo=3321103

Rosen, S. i Tesser, A. (1970). On Reluctance to Communicate Undesirable Information: The MUM Effect. Sociometry, 33(3), 253. https://doi.org/10.2307/2786156

Rubio Arribas, V., Sampedro Martínez, E., Zapirain Sarasola, M., Gil Benito, I., Ayechu Redin, S. i TAPIZ IBÁÑEz, V. (2004). Diagnóstico: cáncer. ¿Queremos conocer la verdad? Atención Primaria, 33(7), 368-373. https://www.elsevier.es/es-revista-atencion-primaria-27-pdf-13060758

RusselL, B. J. i WARD, A. M. (2011). Deciding what information is necessary: Do patients with advanced cancer want to know all the details? Cancer Management and Research, 3(1), 191-199. https://doi.org/10.2147/CMR.S12998

SANDERS, J. (2015). Finding the Right Words at the Right Time - High-Value Advance Care Planning. New England Journal of Medicine, 372(7), 598-599. 
Scarff, C. E., Bearman, M., Chiavaroli, N. i Trumble, S. (2019). Keeping mum in clinical supervision: private thoughts and public judgements. Medical Education, 53(2), 133-142. https://doi.org/10.1111/medu.13728

Sмiтн, R. (2001). Why are doctors so unhappy? There are probably many causes, some of them deep. BMJ, 322(7294), 1073-1074. https://doi.org/10.1136/bmj.322.7294.1073

Sobrino López, A. (2008). Comunicación de malas noticias. Seminarios de La Fundacion Espanola de Reumatologia, 9(2), 111-122. https://doi.org/10.1016/S1577-3566(o8)74928-5

Sullivan, R. J., Menapace, L. W. i White, R. M. (2001). Truth-telling and patient diagnoses. Journal of Medical Ethics, 27(3), 192-197. https://doi.org/10.1136/jme.27.3.192

Tanco, K., Rhondali, W., Perez-Cruz, P., Tanzi, S., Chisholm, G. B., Baile, W., Frisbee-Hume, S., Williams, J., Masino, C., Cantu, H., Sisson, A., Arthur, J. i Bruera, E. (2015). Patient perception of physician compassion after a more optimistic vs a less optimistic message: A randomized clinical trial. JAMA Oncology, 1(2), 176-183. https://doi.org/10.1001/jamaoncol.2014.297

VandeKieft, G. K. (2001). Breaking bad news. Am Fam Physician, 64. https://pubmed.ncbi.nlm.nih.gov/11775763/ 